\title{
Hubungan Pengetahuan Antenatal Care Dengan Kepatuhan Kunjungan Ibu Hamil Pada Kehamilan Trimester III Di BPM Sri Maryani
}

\author{
Anggraini Dyah Setiyarini \\ Program D III Kebidanan Fakultas Ilmu Kesehatan Institut Ilmu Kesehatan Bhakti \\ Wiyata Kediri \\ Email : Anggraini@iik.ac.id
}

\begin{abstract}
ABSTRAK
Pelayanan antenatal merupakan prosedur yang secara rutin dilakukan oleh petugas kesehatan dalam membina hubungan yang baik didalam proses pelayanan pada ibu hamil untuk deteksi dini, pengawasan selama kehamilan dan persiapan persalinan. Salah satu faktor yang kurang dimanfaatkan dalam pelayanan antenatal care antara lain rendahnya pengetahuan dan pemahaman ibu hamil.

Tujuan mengetahui hubungan pengetahuan antenatal care dengan kepatuhan kunjungan pada ibu hamil dengan kehamilan trimester ketiga di BPM Sri Maryani.

Metode penelitian menggunnakan pendekatan cross-sectional, pemilihan sampel dengan menggunakan total sampling. Sampel 30 responden. Pengumpulan semua data dilakukan dengan cara pengisian kuesioner yang telah dibuat oleh peneliti dan diisi oleh responden. Pengolahan data menggunakan program SPSS untuk dianalisi dengan uji Chi Square dengan tingkat kemaknaan $(\alpha) 0,05$.

Hasil penelitian menunjukan bahwa pengetahuan dengan kategori baik 26,7\% (8 Orang), cukup 66,7\% (20 orang) dan kurang 6,7\% (7 orang). Untuk kepatuhan kunjungan antenatal care kategori patuh $76,6 \%$ (23 orang) dan tidak patuh $23,3 \%$ (7 orang).

Kesimpulan terdapat hubungan antara pengetahuan antenatal care dengan kepatuhan kunjungan ibu hamil. Saran supaya meningkatkan mutu pelayanan kehamilan.
\end{abstract}

Kata kunci : Pengetahuan, Kepatuhan, Pemeriksaan antenatal care

\section{ABSTRACT}

Antenatal care is a procedure that is routinely carried out by health workers in developing good relationships in the process of service to pregnant women for early detection, supervision during pregnancy and childbirth preparation. One of the factors that are underutilized in antenatal care services includes low knowledge and understanding of pregnant women.

Objectives is To analyze the relationship between knowledge of pregnant woman with antenatal care in checking the regularity of the Clinics Sri Maryani.

Crossectional the selection of samples with a total sampling. 30 sample respondents. Data collactioan is carried out by filling a question naire made by researchers and is completed by respondents. Collected data is processed further using the computer program SPSS version aid 16 for analysis by Chi Square test with significance level ( $\alpha$ ) 0.05.

Statistical test results using Chi Square Research results show that knowledge with a good ragular category $26,7 \%$ (8 people), enough 66,7\% (20 people), and less well 6,7\% (7 
people). To order check antenatal care regular category 76,7\% (23 people) and irregular 23,3\% (7 people).

Conclusions in this study is the relationship between knowledge of pregnant woman with antenatal care checkups regularity.

Knowledge, regularity, checkings antenatal care

\section{PENDAHULUAN}

Data laporan WHO pada tahun 2015 Angka Kematian Ibu (AKI) di dunia yakni sebesar 46 per seribu kelahiran hidup dan kematian bayi khususnya neonatus sebesar 20 per 1.000 kelahiran hidup (WHO, 2015). Berdasarkan Data Kementrian Kesehatan RI 2017 menyebutkan bahwa AKI di Indonesia pada tahun 2016 sebanyak 305 kematian per 100.000 kelahiran hidup. Cakupan presentase cakupan pelayanan KI di Kediri pada tahun 2016 sebesar $4.596(97,21 \%)$ dan cakupan K4 di Kediri pada tahun 2016 sebesar $4.348(91,96 \%)$ dari seluruh ibu hamil sebanyak 4.728 orang. (Dinkes, 2017). Data ibu hamil di BPM Sri Maryani Desa Tiron Kec. Banyakan Kab. Kediri 2015 terdapat sebanyak 105 ibu hamil dan yang melakukan KI (Kunjungan Ke-1) sebanyak 89,52\% dan K4 (Kunjungan Ke4) sebanyak 91,42\%. Kurangnya pemahaman tentang pedoman Kesehatan Ibu dan Anak (KIA) merupakan salah satu penyebab rendahnya kunjungan antenatal careI, olehkarenanya masih saja terdapat ibu hamil yang tidak melaksanakan kunjungan pemeriksaan kehamilan secara teatur (Salman dkk, 2013). Upaya meningkatkan kepatuhan kunjungan antenatal care yaitu dengan meningkatkan penyuluhan terhadap masyarakat serta melakukan komunikasi dan edukasi intensif terhadap ibu hamil serta keluarganya berdasarkan standar (Dinkes, 2010). Standar Asuhan pada ibu hamil yang dimaksud difokuskan pada promosi kesehatan, pendidikan kesehatan serta pencegahan terhadap suatu penyakit (Megasari dkk, 2015) Berdasarkan uraian diatas peneliti ingin mengetahui bagaimana hubungan pengetahuan antenatal care dengan kepatuhan kunjungan ibu hamil pada kehamilan trimester III di BPM Sri Maryani.

\section{METODE PENELITIAN}

Desain Penelitian pada penelitian ini menggunakan cross sectional. Populasi meliputi semua ibu hamil trimester III yang memeriksakan kehamilan di BPM Sri Maryani. Jumlah sampel sebanyak 30 responden. Tehnik sampling yang digunakan adalah total smapling. Kriterian inklusi yakni ibu hamil trimester III yang memriksakan kehamlannya di BPM Sri Maryani, bersedia menjadi reponden, dapat berkomunikasi secara verbal. Penelitian ini menggunakan uji Chi Square.

\section{HASIL PENELITIAN}

\begin{tabular}{cccc}
$\begin{array}{l}\text { Tabel } \\
\text { berdasarkan } \\
\text { antenatal care }\end{array}$ & $\begin{array}{c}\text { Karakteristik } \\
\text { pengetahuan }\end{array}$ & $\begin{array}{c}\text { responden } \\
\text { tentang }\end{array}$ \\
\hline No & Kriteria & Jumlah & $\begin{array}{c}\text { Presentase } \\
(\%)\end{array}$ \\
\hline 1. & Baik & 8 & $26,6 \%$ \\
2. & Cukup & 20 & $66,7 \%$ \\
3. & Kurang & 2 & $6,7 \%$ \\
\hline & Jumlah & 30 & $100 \%$ \\
\hline
\end{tabular}

Berdasarkan tabel 1. Karakteristik responden berdasarkan pengetahuan tentang antenatal care sebagian besar responden memiliki penetahuan cukup sebanyak $66,7 \%$ dari 30 responden. 
Vol. 11 No. 1, Juni 2019

Tabel 2. Kepatuhan antenatal care berdasarkan kunjungan antenatal care

\begin{tabular}{|c|c|c|c|c|}
\hline No & Kriteria & Jumlah & \multicolumn{2}{|c|}{$\begin{array}{c}\text { Presentase } \\
(\%)\end{array}$} \\
\hline 1. & Patuh & 23 & \multicolumn{2}{|c|}{$76,7 \%$} \\
\hline 2. & $\begin{array}{l}\text { Tidak } \\
\text { Patuh }\end{array}$ & 7 & \multicolumn{2}{|c|}{$23,3 \%$} \\
\hline \multicolumn{2}{|c|}{ jumlah } & 30 & \multicolumn{2}{|c|}{$100 \%$} \\
\hline \multicolumn{5}{|c|}{ 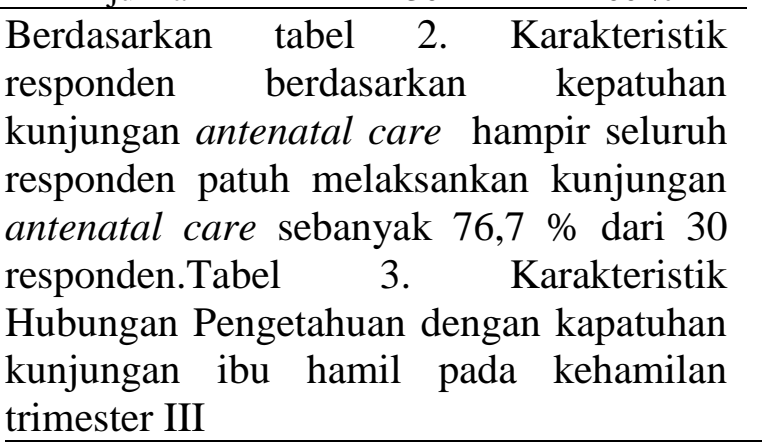 } \\
\hline \multirow{2}{*}{\multicolumn{2}{|c|}{ Pengetahuan }} & \multicolumn{2}{|c|}{ Kunjungan ANC } & \\
\hline & & Patuh & $\begin{array}{l}\text { Tidak } \\
\text { Patuh }\end{array}$ & \\
\hline baik & $\begin{array}{c}\text { Count } \\
\% \text { of Total }\end{array}$ & $\begin{array}{c}8 \\
26.7 \%\end{array}$ & $\begin{array}{c}0 \\
0 \%\end{array}$ & $\begin{array}{c}8 \\
26.6 \%\end{array}$ \\
\hline cukup & $\begin{array}{c}\text { Count } \\
\% \text { of Total }\end{array}$ & $\begin{array}{c}15 \\
50 \% \\
\end{array}$ & $\begin{array}{c}5 \\
16.7 \% \\
\end{array}$ & $\begin{array}{c}20 \\
66.7 \% \\
\end{array}$ \\
\hline kurang & $\begin{array}{c}\text { Count } \\
\% \text { of Total }\end{array}$ & $\begin{array}{c}0 \\
0 \% \\
\end{array}$ & $\begin{array}{c}2 \\
6.7 \% \\
\end{array}$ & $\begin{array}{c}2 \\
6.7 \% \\
\end{array}$ \\
\hline Total & $\begin{array}{c}\text { Count } \\
\% \text { of Total }\end{array}$ & $\begin{array}{c}23 \\
76.7 \% \\
\end{array}$ & $\begin{array}{c}7 \\
23.3 \% \\
\end{array}$ & $\begin{array}{c}30 \\
100 \% \\
\end{array}$ \\
\hline
\end{tabular}

$\mathrm{P}-$ Value $=0,011$

Berdasarkan tabel 3. Hasil uji diperoleh nilai $\rho=0,011$. Nilai $\rho<\alpha(0,05)$ dengan demikian $\mathrm{H} 1$ dan $\mathrm{H} 0$ ditolak.

\section{PEMBAHASAN}

Dari data hasil penelitian diperoleh sebagian besar responden memiliki pengetahuan cukup yaitu $66,7 \%$ dari 30 responden. Pengetahuan merupakan salah satu indikator dalam melaksanakan suatu tindakan. Semakin tinggi pengetahuan ibu hamil tentang antenatal care maka akan berpengaruh terhadap memeriksakan kehamilannya dan semakin tinggi tingkat kepatuhan kunjungan antenatal care. (Salman dkk, 2013). Pada penelitian terdahulu sebagian besar responden memiliki pengetahuan cukup dikarenakan beberapa faktor. Faktor yang memungkinkan adalah mudahnya memperoleh informasi sehingga akan mempengaruhi seseorang untuk menambah pengetahuan tentang antenatal care; tingkat pendidikan responden sebagian besar sekolah menengah akan mempengaruhi cara berfikir responden untuk memperoleh berbagai macam informasi dan faktor pengalaman dari kehamilan terdahulu.

Dari data hasil penelitian diperoleh hampir seluruh responden kepatuhan kunjungan antenal care baik yakni sebanyak 76,7 \% dari 30 responden dan sebagian kecil nilai kepatuhan kunjungan Iantenatal care tidak patuh yakni sebnayak 23,3\% dari 30 responden. Ibu hamil yang patuh melakukan antenatal care akan banyak memperoleh informasi diantaranya mengenai cara menjaga kehamilan, mendapatkan bantuan profesional sesegera mungkin jika terjadi masalah pada kehamilannya dan mendapat pelayanan kesehatan (Hardiani dkk, 2012). Kepatuhan mempengaruhi cakupan nilai kunjungan antenatal care ibu hamil. Ibu hamil yang teratur melakukan kunjungan antenatal care akan memiliki pola fikir dengan melakukan kunjungan antenatal care secara teratur maka dia akan memliki kemudahan dalam bersikap cara mengatasi masalah kehamilan yang dihadapinya sehingga jika ibu hamil tersebut sedang mengalami masalah kehamilan maka segera menghubungi tenaga kesehatan yang profesional dan masalah tersebut segera tertangani oleh tenaga kesehatan.

Pada penelitian ini hampir seluruh responden patuh untuk melakukan kunjungan antenatal care disebabkan oleh beberapa faktor. Faktor yang utama adalah sebagian besar reponden memiliki pengetahuan cukup tentang antenatal care. Sebagian kecil responden tidak patuh dalam melakukan kunjungan antenatal care, hal ini dipengaruhi oleh faktor pendidikan responden yang rendah dan kehamilan multigravida. Pendidikan rendah sangat memprengaruhi dalam keputusan melakukan kunjungan antenatal care. Multigravida membuat responden 
beranggapan bahwa kehamilan kali ini seperti kehamilan sebelumnya sehingga tidak pelu melakukan kunjungan antenatal care. Padahal setiap kehamilan tidak boleh disamakan karena setiap kehamilan mempunyai faktor resiko yang berbeda.

Berdasarkan uji Chi Squre dengan SPSS diperoleh hasil $\rho<\alpha, \quad \rho=0,011$ $\alpha=0,05$. H1 diterima, terdapat hubungan antara pengetahuan antenatal care dengan kepatuhan ibu hamil pada kehamilan trimester III di BPM Sri Maryani kabupaten kediri.

Pengetahuan dipengaruhi oleh informasi yang telah didapatkan oleh responden. Menurut Pampel (2010) informasi yang telah didaptkan oleh seseorang dapat mengubah yang awalnya tidak "tahu" menjadi "tahu" dan mengerti sehingga akan mengubah sistem pemikiran responden, responden kali ini adalah ibu hamil atas kehamilannya. Sehingga mereka akan bersikap sesuai dengan pengetahuan yang telah mereka miliki dan berpengaruh terhadap nilai kepatuhan untuk melakukan kunjungan antenatal care (pradono dkk, 2013). Pelayanan antenatal care dan pemberian informasi dari petugas kesehatan merupakan pelayanan komprehensif yang berkualitas diberikan kepada seluruh ibu hamil. Sehingga seluruh ibu hamil lebih memahami kehamilannya dan jika sewaktu-waktu terdapat masalah didalam kehamilannya. Oleh karenanya, antenatal care harus dilakukan secara rutin oleh seluruh ibu hamil dan harus sesuai denganstandart pelayanan antenatal care yang berkualitas (Kemenkes, 2012)

Adanya hubungan signifikan pada penelitian ini menunjukkan bahwa pengetahuan ibu hamil tentang antenatal care cukup menjadikan tingkat kepatuhan dalam kunjungan antenatal care sesuai dengan standart. Responden yang patuh melakukan kunjunan antenatal care akan lebih mudah mendapatkan pengetahuan tentang kehamilan dan dengan intensif memantau kondisi kesehatan dirinya serta dapat memantau pertumbuhan dan perkembangan janin. Sehingga dapat menjalani masa kehamilan tanpa adanya komplikasi. Seiring dengan perkembangan tehnologi semua ibu hamil dimudahkan dalam mencari sumber informasi dan pengatahuan, juga dengan fasilitas pelayanan kesehatan yang ada secara menyeluruh baik di desa maupun pelosok hingga kota. Sehingga memudahkan tingkat kepatuhan kunjungan antenatal care semakin meningkat dan harapannya bisa menurunkan AKI dan AKB di Indonesia.

\section{KESIMPULAN DAN SARAN KESIMPULAN}

Dari hasil penelitian diperoleh yakni pengetahuan tentang antenatal care di BPM Sri Haryani dengan kategori cukup. Kepatuhan kunjungan antenatal care pada kehamilan trimester III di BPM Sri Maryani berada didalam kategori patuh. Dan berdasarkan uji korelasi Chi Square terdapat hubungan pengetahuan antenatal care dengan kepatuhan kunjungan ibu hamil pada kehamilan trimester III di BPM Sri maryani.

\section{SARAN}

1. Diharapkan unutk penelitian yang telah dilakukan ini dapat digunakan sebagai bahan pertimbangan dan pengembangan untuk penelitianselanjutnya.

2. Penelitian yang akan mendatang diharapkan menggunakan instrumen dan metode penelitian yang lebh lengkap dan terbaru.

\section{DAFTAR PUSTAKA}

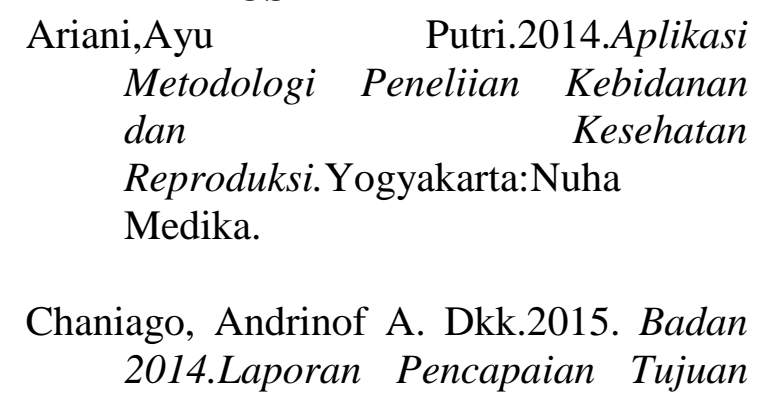


Vol. 11 No. 1, Juni 2019

\section{Pembagungan Milenium di Indonesia.Jakarta:Kementrian \\ Perencanaan Pembangunan \\ Nasional/Badan Perencanaan \\ Nasional/Badan Perencanaan \\ Pembangunan Nasional(BAPENAS).}

Dinas Kesehatan Provinsi Jawa Timur.2018. Profil Kesehatan Kabupaten Kediri. Surabaya:Badan Penerbit Dinas Kesehatan Provinsi Jawa Timur.

Hardiani, R. S dan Purwanti, A.2012. Motivasi danKepatuhan Kunjungan Antenatal Care(ANC) pada Ibu Hamil Trimester III Jurnal Keperawatan, 3(2), 184.

Indriyani,D.2013.Keperawatan

Maternanitas $\quad$ padar Area
Peratawatan
Graha Ilmu.

Kemenkes RI. 2012.Petunjuk Kerja Pelayanan Antenatal Terpadu persalinan dan Pasca Persalinan Terpadu.Jakarta:Kementrian

Kesehatan Republik Indonesia, MCHIP-USAID.

Kemenkes RI. 2014. Health Statistics. Jakarta : Kementrian Kesehatan Republik Indonesi.

Lisnawati, L. 2013. Asuhan Kebidanan Terkini Kegawatdaruratan Maternal dan Neonatal. Jakarta : CV. Trans Info Media.

Megasari, Miratu dkk. 2015. Panduan Belajar Asuhan Kebidanan I. Yogayakarta : CV Budi Utama.

Pradono,J\&Sulistyawati,N.2014.Hubunga $n$ antara Tingkat Pendidikan, Pengetetahuan tentang Kesehatan Lingkungan, Perilaku Hidup Sehat dengan Status Kesehatan. Buletin
Penelitian Sistem Kesehatan, 17 (1), 91-93.

Salman, dkk. 2013. Faktor yang Berhubungan dengan Rendahnya K4 Ibu Hamil dan Ibu Nifas di Puskesmas Belawan Kabupaten Wajo. Jurnal Kesehatan, 1(6), 6.

World Health Organization Millenium Development Goal 5 Fact Sheet. www.who.int. [diakses tanggal $9 \mathrm{Mei}$ 2016, pukul 14.00 WIB] 